\title{
Catamenial hemoptysis and pneumothoraces in a patient with cystic fibrosis
}

\author{
Chris M Parker MD MSc ${ }^{1}$, Robert Nolan $\mathrm{MD}^{2}, \mathrm{M}^{2}$ Diane Lougheed MD MSc${ }^{1}$
}

CM Parker, R Nolan, MD Lougheed. Catamenial hemoptysis and pneumothoraces in a patient with cystic fibrosis. Can Respir J 2007;14(5):295-297.

Hemoptysis or pneumothorax that recurs with the onset of menses is strongly suggestive of thoracic endometriosis syndrome (TES). TES is a rare disorder, with relatively few cases reported in the literature. A 32-year-old woman with cystic fibrosis, who over a period of several months had experienced recurrent catamenial hemoptysis and pneumothoraces, including an episode of life-threatening hemoptysis that coincided with menstruation, is presented. Thoracic computed tomography and magnetic resonance imaging scans, as well as a bronchosopic evaluation that demonstrated endobronchial lesions that disappeared after menses, support the diagnosis of TES in the present patient. The patient was treated empirically with danazol and subsequently underwent a successful double-lung transplantation. Danazol was discontinued postoperatively, and she was started on an oral contraceptive. Eighteen months post-transplant, she has not experienced a recurrence of her catamenial symptoms, despite having resumed a regular menstrual cycle.

\section{Des hémoptysies et des pneumothorax cataméniaux chez une patiente atteinte de fibrose kystique}

Une récurrence d'hémoptysies ou de pneumothorax à l'apparition des menstruations est fortement évocatrice d'une endométriose thoracique (ET). L'ET est un trouble rare, et relativement peu de cas ont été déclarés dans les publications. Est présenté le cas d'une femme de 32 ans atteinte de fibrose kystique qui, pendant plusieurs mois, a souffert d'hémoptysies et de pneumothorax cataméniaux récurrents, y compris un épisode d'hémoptysie mettant sa vie en danger qui a coïncidé avec ses menstruations. La tomodensitométrie thoracique, l'imagerie par résonance magnétique et une évaluation bronchoscopique qui ont révélé des lésions endobronchiques qui ont disparu après les menstruations soutenaient le diagnostic d'ET. La patiente a subi un traitement empirique au danazol et a ensuite subi une double greffe pulmonaire réussie. La patiente a cessé de prendre du danazol après l'opération, et on lui a prescrit un contraceptif oral. Dix-huit mois après la greffe, elle n'avait vécu aucune récurrence des symptômes cataméniaux, même si elle avait retrouvé un cycle menstruel régulier.

Key Words: Catamenial; Cystic fibrosis; Hemoptysis

Catamenial hemoptysis and pneumothorax are rare condiUtions that occur as part of the thoracic endometriosis syndrome (TES), and are characterized by symptoms that occur or recur during menses. Catamenial pneumothorax is the most common presentation of TES, accounting for approximately $80 \%$ of the reported cases (1). Of the cases of catamenial hemoptysis described in the literature, none has described the occurrence of life-threatening hemoptysis. TES often occurs without evidence of pelvic endometriosis (2), and the etiology, diagnostic criteria and optimal treatment of TES remain controversial. In the present report, a patient with cystic fibrosis (CF) and a history of catamenial pneumothoraces, who presented with life-threatening catamenial hemoptysis, is presented.

\section{CASE PRESENTATION}

Over several months, a 32-year-old woman with CF ( $\triangle F 508$, $\Delta \mathrm{I} 507$ genotype) experienced several episodes of mild, streaky hemoptysis and two episodes of spontaneous left pneumothorax, which coincided with the onset of menses. She was nulligravid, had no known previous history of pelvic endometriosis nor any history of pelvic pain, dysmenorrhea or uterine manipulation. In September 2004 she had developed sudden massive hemoptysis on the second day of menses. Immediately following this episode, she had collapsed and required resuscitation. The volume of blood expectorated was estimated to be approximately $500 \mathrm{~mL}$ and was associated with an acute fall in hemoglobin concentration of $18 \mathrm{~g} / \mathrm{L}$. Before this event, she was relatively well; her baseline lung function had remained stable (forced expiratory volume in 1 s $32 \%$ of predicted), and there were no symptoms to suggest an antecedent infectious exacerbation. She was nonetheless treated with antibiotics and had recovered. With the onset of her next menstrual cycle, she experienced recurrent streaky hemoptysis. Bronchial arterial angiography demonstrated the presence of an extensive collateral circulation, and several ectatic arteries were embolized. A computed tomography (CT) scan obtained during menses demonstrated the presence of pulmonary parenchymal lesions, consistent with hemorrhage, that resolved completely on a follow-up CT scan obtained midway through her menstrual cycle (Figure 1). Thoracic magnetic resonance imaging, obtained during menses, demonstrated

${ }^{1}$ Department of Medicine; ${ }^{2}$ Department of Radiology, Queen's University, Kingston, Ontario

Correspondence: Dr Chris M Parker, Division of Respiratory and Critical Care Medicine, Department of Medicine, Queen's University, 102 Stuart Street, Kingston, Ontario K7L 2V6. Telephone 613-548-2384, fax 613-549-1459, e-mail parkerc@post.queensu.ca 

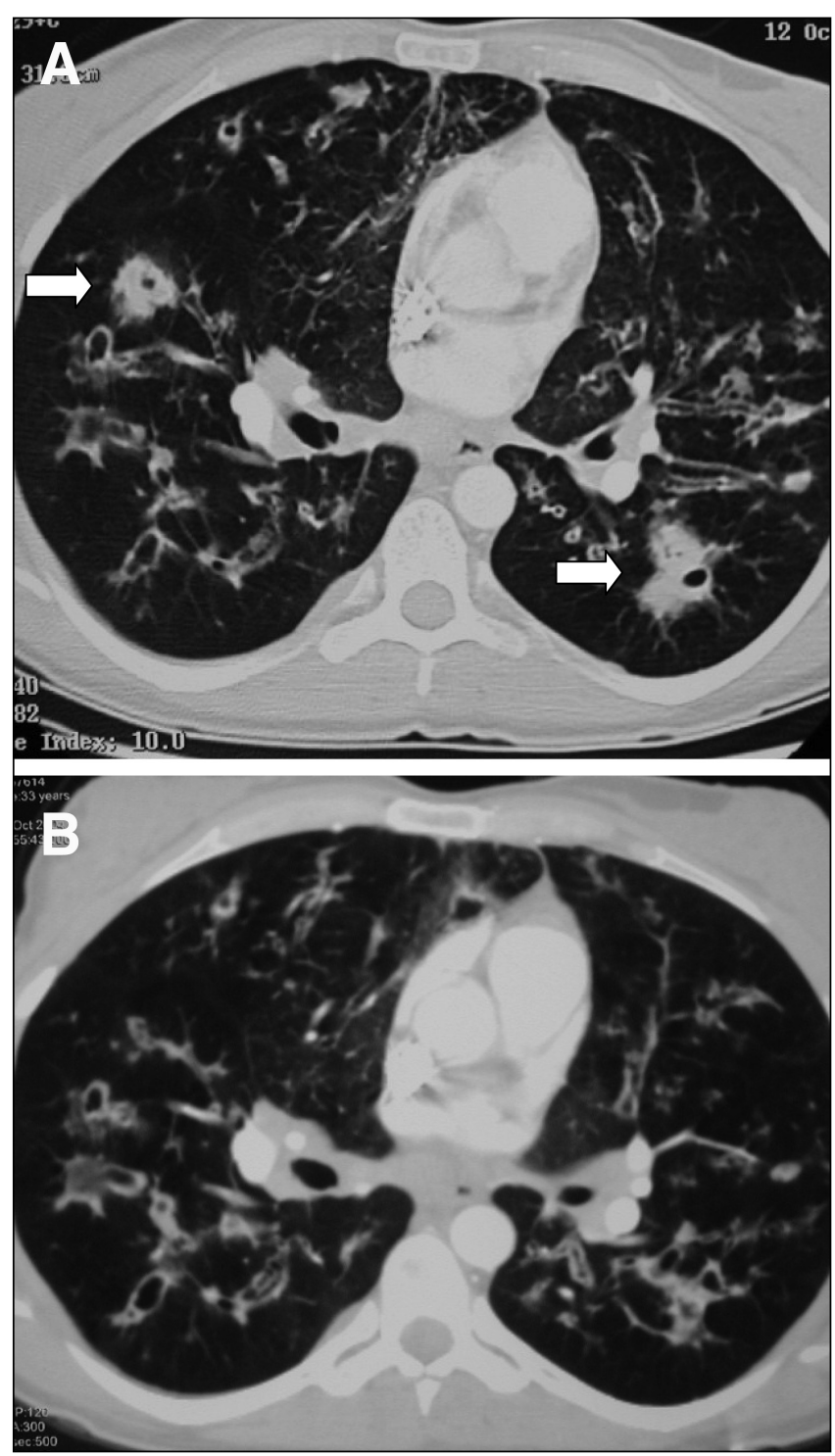

Figure 1) Corresponding slices of thoracic computed tomography scans taken during menses (A) and mid-cycle (B). Images taken during menses demonstrated the presence of pulmonary parenchymal lesions (white arrows) consistent with hemorrhage, which were no longer evident on a scan taken approximately two weeks later when the patient was mid-cycle

hyperintense lesions (consistent with hemorrhage or endometrial tissue) that had localized to her left apical pleura. Bronchoscopy, performed premenstrually, showed at least two friable purplish lesions in her segmental bronchi, which were no longer evident after menses. Bronchial washings did not show endometrial cells. At the patient's request, neither biopsies nor brushings were performed. Given the strong clinical suspicion of TES, she was started empirically on danazol and became amenorrheic. She experienced another episode of lifethreatening hemoptysis approximately three months after starting danazol therapy coincident with an infectious exacerbation of $\mathrm{CF}$, and subsequently underwent double-lung transplantation. Histological evaluation of her native lungs did not demonstrate the presence of endometrial tissue. Danazol treatment was discontinued postoperatively, and the patient was started on an oral contraceptive. Twenty-four months post-transplant, she has had no further episodes of hemoptysis or pneumothoraces, despite having resumed menses.

\section{DISCUSSION}

To our knowledge, this is the first report of catamenial hemoptysis and pneumothoraces occurring in a patient with CF. In the present patient, the clinical history, as well as the dynamic radiographic and bronchoscopic appearance, strongly suggest a diagnosis of TES. Although we were unable to exclude an infectious exacerbation of the underlying $\mathrm{CF}$, the lack of clinical symptoms to suggest an infectious etiology, as well as the recurrent catamenial nature of both the hemoptysis and the pneumothoraces, did not favour this diagnosis. Nonetheless, she was treated empirically with antibiotics. Furthermore, she was known to be colonized with Aspergillus fumigatus, but had experienced recurrent hemoptysis, despite initiation of treatment with itraconazole. Although a definitive histopathological diagnosis was not obtained, it should be noted that in approximately two-thirds of the cases of TES reported in the literature, diagnosis was established based on historical and clinical criteria alone (3). Furthermore, treatment with danazol has been demonstrated to result in macroscale regression of ectopic endometriomas, which may have made pathological confirmation more difficult in the present case (4). The fact that this patient experienced both catamenial hemoptysis and pneumothoraces suggested that ectopic endometriomas had localized to both pleura and pulmonary parenchyma, which has also been previously described $(2,5)$. In previous reports (1), the volume of blood expectorated in the setting of catamenial hemoptysis was usually less than $200 \mathrm{~mL}$, and life-threatening hemoptysis has hitherto not been described. We propose that the massive nature of the hemoptysis experienced by our patient may be a consequence of the bronchial arterial collateral circulation (visualized angiographically) that had developed due to her underlying bronchiectasis. Interestingly, although it is generally accepted that the most likely etiology of catamenial hemoptysis is TES, there is a single case report (3) in the literature of a pulmonary arteriovenous malformation presenting with cyclical bleeding coincident with menses. This may suggest that in some disease processes, at least, the pulmonary vasculature may be sensitive to hormonal changes, and it is therefore possible that such a mechanism was affecting the ectatic bronchial circulation in our patient. However, this possibility would not be expected to explain the occurrence of catamenial pneumothoraces.

The optimal treatment of TES is uncertain, with surgical resection and ovarian suppression being the most widely reported $(1,6)$. Danazol is reported to be effective, although treatment failures have been described (7). Other treatments reported to be successful include gonadotropin-releasing hormone antagonists, oral contraceptives, estrogen subdermal implants or the use of clomiphene citrate therapy $(1,8)$. More recently, the use of endobronchial laser ablation has been described for lesions that are detected bronchoscopically $(9,10)$. In some cases, at least, there may also be spontaneous resolution or improvement in symptoms, even in the absence of therapy (11).

Bronchoscopic findings in patients with catamenial hemoptysis and presumed TES are variable. Multiple bilateral purplish-red submucosal lesions are most commonly described, but appearances ranging from a single tiny red mucosal lesion (9) to diffuse mucosal hyperemia (8) have been reported. The 
yield of bronchial biopsy in establishing the diagnosis of TES is curiously low, although cytological analysis of samples obtained with brush biopsy may be more sensitive. However, as in our patient, follow-up bronchoscopic examination performed postmenstrually or in mid-cycle typically demonstrates resolution of previously visualized lesions (8). Similarly, radiographic appearance on chest CT scans can be variable, but may include ill-defined parenchymal opacities, nodular lesions or ground glass opacifications; these lesions are often dynamic and change with the menstrual cycle.

Controversy also exists in terms of the presumed etiological mechanisms by which ectopic endometrial tissue arises in the thorax; three theories have been proposed $(1,12)$. The theory of coelomic metaplasia maintains that uterine endometrium and pleural mesothelium share the same embryological origin, and undefined pathogenic stimuli may result in the differentiation of pleural-based precursor cells into endometrial cells. However, this does not explain the occurrence of intrapulmonary endometriosis. The second theory is that of the transdiaphragmatic passage of endometrial cells through diaphragmatic defects; this too could explain pleural deposits of endometrium but would not be expected to result in intraparenchymal pulmonary deposits. The third theory suggests that endometrial cells may embolize from the pelvis to other extrauterine or extrapelvic sites by using the lymphatics or the bloodstream. Alternatively, ectopic endometrium that arises in the pleural space as a consequence of another mechanism (such as transdiaphragmatic passage of endometrium) could embolize via regional lymphatics. This mechanism could explain the development of multiple sites of ectopic endometrium, including intraparenchymal lung lesions. However, none of these theories can in isolation explain all of the clinical manifestations of TES, and the etiology may be multifactorial. In the present patient, the risk of recurrence of pulmonary endometriosis in the lung allograft is unknown.

\section{REFERENCES}

1. Alifano M, Trisolini R, Cancellieri A, Regnard JF. Thoracic endometriosis: Current knowledge. Ann Thorac Surg 2006;81:761-9.

2. Alifano M, Roth T, Broët SC, Schussler O, Magdeleinat P, Regnard JF. Catamenial pneumothorax: A prospective study. Chest 2003;124:1004-8.

3. Wood DJ, Krishnan K, Stocks P, Morgan E, Ward MJ. Catamenial haemoptysis: A rare cause. Thorax 1993;48:1048-9.

4. Dmowski WP, Cohen MR. Treatment of endometriosis with an antigonadotropin, Danazol. A laparoscopic and histologic evaluation. Obstet Gynecol 1975;46:147-54.

5. Morcos M, Alifano M, Gompel A, Regnard JF. Life-threatening endometriosis-related hemopneumothorax. Ann Thorac Surg 2006;82:726-9.

6. Ziedalski TM, Sankaranarayanan V, Chitkara RJ. Thoracic endometriosis: A case report and literature review. J Thorac Cardiovasc Surg 2004;127:1513-4.

7. Joseph J, Sahn SA. Thoracic endometriosis syndrome: New observations from an analysis of 110 cases. Am J Med 1996;100:164-70.

8. Hope-Gill B, Prathibha BV. Catamenial haemoptysis and clomiphene citrate therapy. Thorax 2003;58:89-90.

9. Puma F, Carloni A, Casucci G, Puligheddu C, Urbani M, Porcaro G. Successful endoscopic Nd-YAG laser treatment of endobronchial endometriosis. Chest 2003;124:1168-70.

10. Ozvaran MK, Baran R, Sogukpmar O, et al. Histopathological diagnosis of endobronchial endometriosis treated with argon laser. Respirology 2006;11:348-50.

11. Ryu JS, Song ES, Lee KH, Cho JH, Kwak SM, Lee HL. Natural history and therapeutic implications of patients with catamenial hemoptysis. Respir Med 2006;101:1032-6

12. Olive DL, Schwartz LB. Endometriosis. N Engl J Med 1993;328:1759-69. 


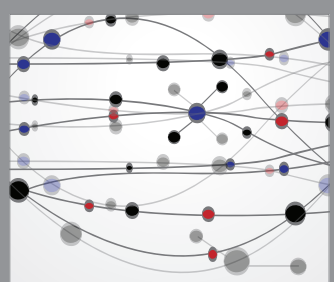

The Scientific World Journal
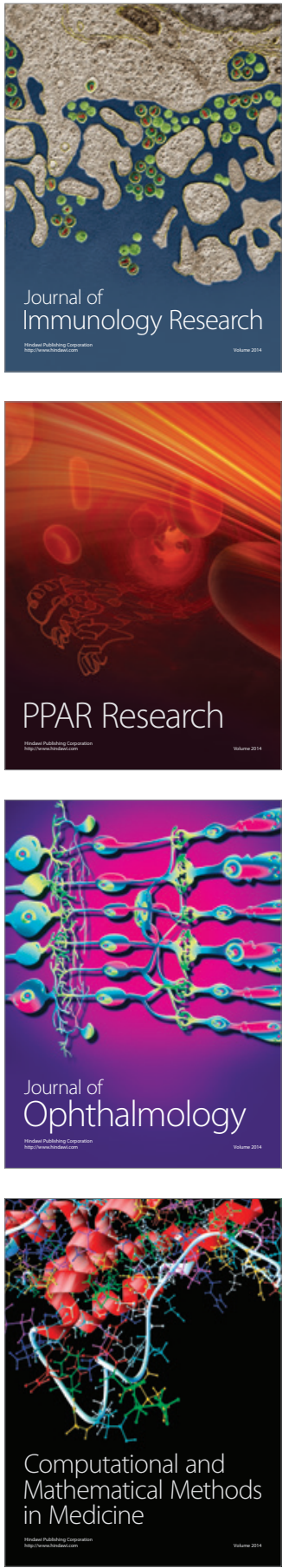

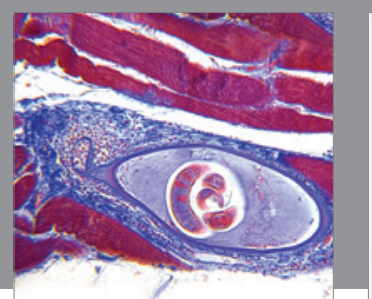

Gastroenterology Research and Practice

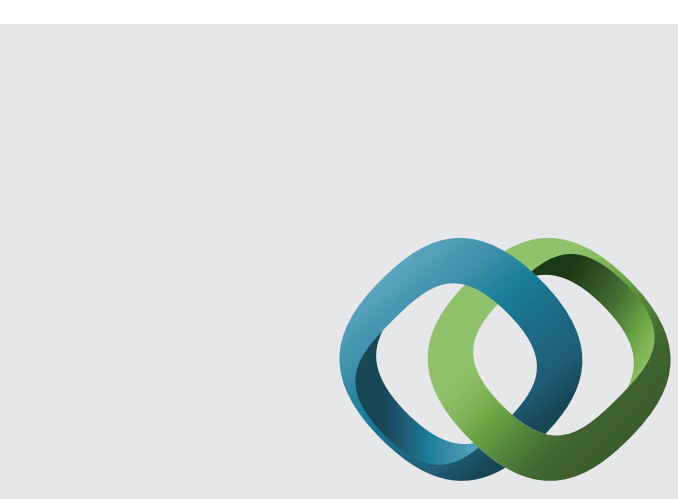

\section{Hindawi}

Submit your manuscripts at

http://www.hindawi.com
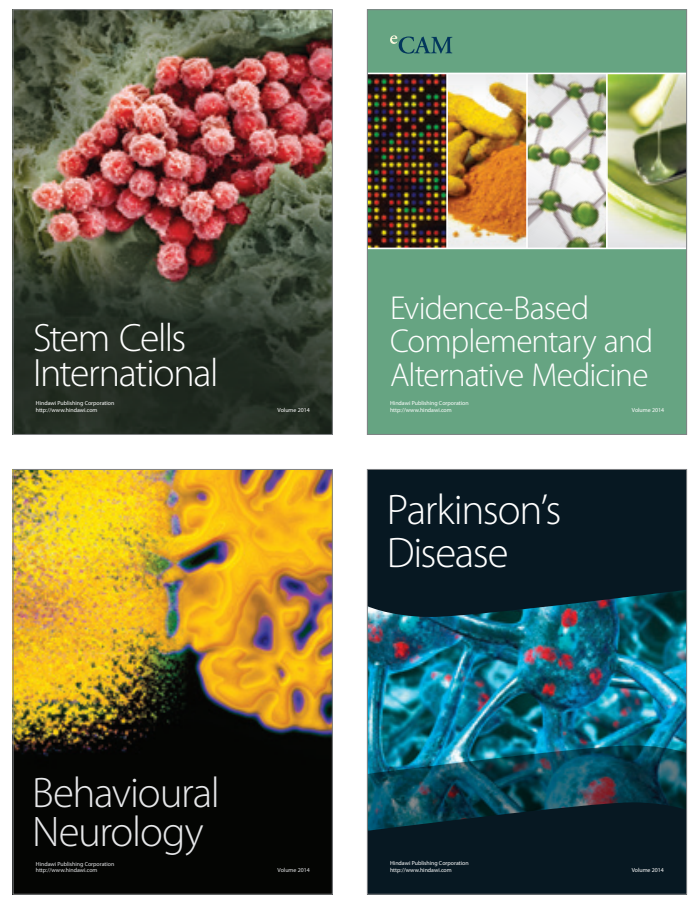
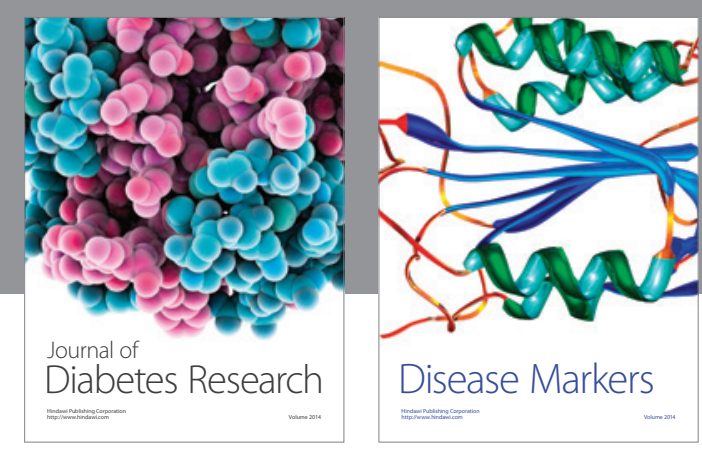

Disease Markers
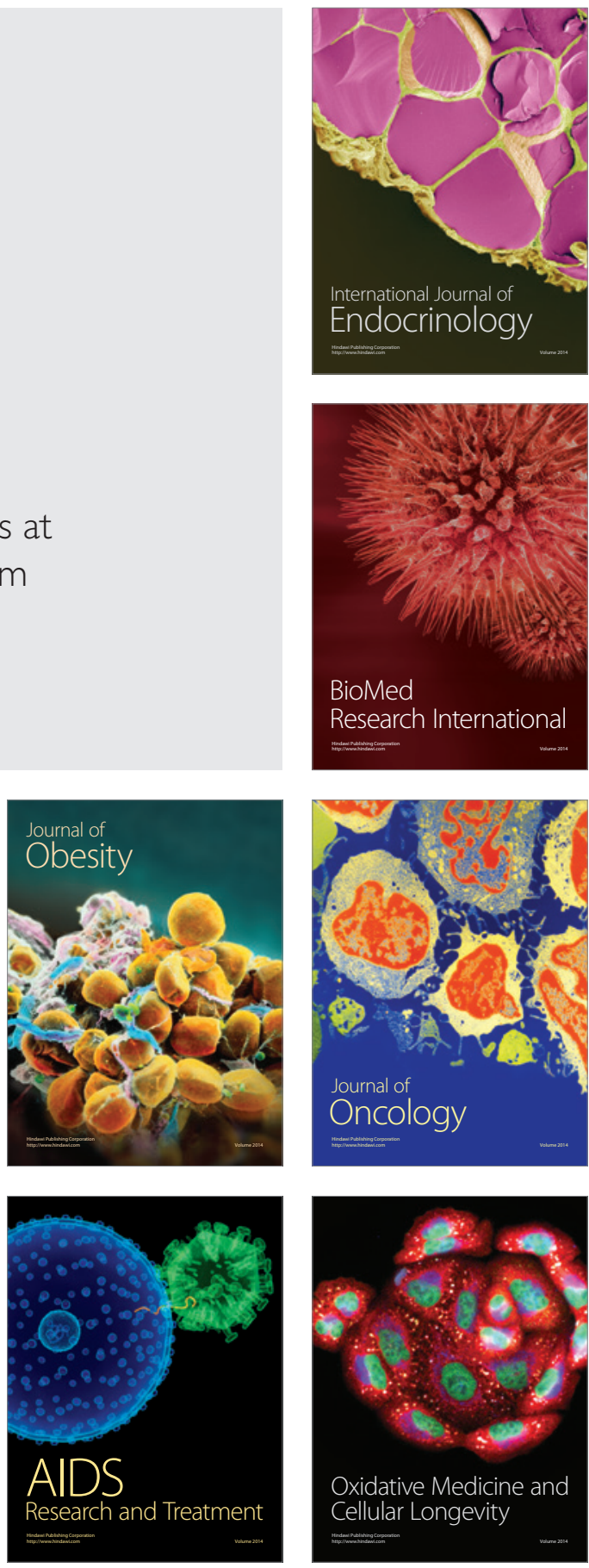